\title{
Adsorption and Dissociation of a Bicyclic Tertiary Diamine, Triethylenediamine, on a Si(100)-2 $\times 1$ Surface
}

\author{
Jing Zhao, ${ }^{\dagger}$ Mark R. Madachik, ${ }^{\dagger}$ Kane M. O’Donnell, ${ }^{\ddagger}$ Gareth Moore, ${ }^{\S, \|}$ L. Thomsen, ${ }^{\perp}$ \\ Oliver Warschkow, ${ }^{\#}$ Steven R. Schofield, ${ }^{\S, \|}$ and Andrew Teplyakov*, ${ }^{*}$ \\ ${ }^{\dagger}$ Department of Chemistry and Biochemistry, University of Delaware, Newark, Delaware 19716, United States \\ ${ }^{\ddagger}$ Department of Physics, Astronomy and Medical Radiation Science, Curtin University, Bentley, Western Australia 6102, Australia \\ ${ }^{\S}$ London Centre for Nanotechnology, University College London, London WC1H 0AH, United Kingdom \\ "Department of Physics and Astronomy, University College London, London WC1E 6BT, United Kingdom \\ ${ }^{\perp}$ Australian Synchrotron, Clayton, Victoria 3168, Australia \\ ${ }^{\#}$ Centre for Quantum Computation and Communication Technology, School of Physics, University of Sydney, Sydney, New South \\ Wales 2006, Australia
}

\section{Supporting Information}

ABSTRACT: This study investigates the adsorption and thermal transformations of a bicyclic tertiary amine, triethylenediamine, on the clean $\mathrm{Si}(100)-2 \times 1$ surface. Below room temperature, triethylenediamine adsorption leads to the formation of a strong dative bond between one of the nitrogen atoms of this compound and the silicon surface. In contrast to previously studied amines, the datively adsorbed triethylenediamine features a second tertiary amine entity that is not bonded to the surface, with a lone pair orbital that is directed away from the surface and is available for further reactions. The thermal chemistry and electronic properties of triethylenediamine on silicon are studied using thermal desorption spectroscopy, infrared spectroscopy, and Xray photoelectron spectroscopy. Near-edge X-ray absorption fine structure measurements are utilized to clarify the geometry of the adsorbates at room temperature. Density functional theory calculations are used to describe the binding geometry and electronic properties of the resulting surface species and the likely reaction paths at elevated temperatures.

\section{INTRODUCTION}

Interest in the organic functionalization of semiconductor surfaces has seen tremendous growth over the last several decades due to existing and potential applications in such diverse fields as microelectronics, catalysis, and biosensing. ${ }^{1-8}$ The silicon and germanium surfaces in particular have attracted much attention due to their electronic properties and welldefined reactivity. The clean (100) surfaces of silicon and germanium are characterized by rows of asymmetrically tilted dimers, which can be used as a template to modify the surface using controlled reactions with organic molecules. Recently, in an attempt to create a robust and chemically stable organicinorganic interface, a number of studies have focused on grafting nitrogen-containing molecules onto silicon and germanium. $^{9-22}$ The chemisorption of primary and secondary amines on $\mathrm{Si}(100)$ generally begins with the nitrogen atom forming a dative bond with the down-buckled atom of a silicon dimer, followed by $\mathrm{N}-\mathrm{H}$ dissociation and the transfer of the hydrogen atom to a nearby up-buckled silicon atom. ${ }^{18,22-26}$ The $\mathrm{N}-\mathrm{H}$ dissociation step is governed by the properties of this datively bonded species, as the dative bond weakens the $\mathrm{N}-\mathrm{H}$ bond and increases the nucleophilicity of the up-buckled silicon atom. ${ }^{18}$ In contrast to the $\mathrm{Si}(100)$ surface, primary and secondary amines on the $\mathrm{Ge}(100)$ surface typically form stable datively bonded species without undergoing $\mathrm{N}-\mathrm{H}$ dissociation at room temperature. Bent and co-workers ${ }^{27}$ have rationalized these trends by comparing the nucleophilicity of the $\mathrm{Si}(100)$ and $\mathrm{Ge}(100)$ surfaces and finding that the up-buckled atoms on silicon have a higher proton affinity than those on germanium. Tertiary amines do not have any $\mathrm{N}-\mathrm{H}$ bonds, and the kinetic barriers to $\mathrm{N}-\mathrm{C}$ dissociation are much more prohibitive. ${ }^{18,23}$ This makes tertiary amines an interesting target for investigation with high potential for creating selective surface templates based on the resulting electronic properties of the silicon surface covered with datively bonded adsorbates. For example, the coadsorption of trimethylamine and boron fluoride on the $\mathrm{Si}(100)$ surface leads to the formation of a novel surface-mediated donor-acceptor complex as reported by the Hamers group. ${ }^{28}$ Such a complex would be very difficult to form using primary or secondary amines because the

Received: October 17, 2016

Revised: November 22, 2016

Published: November 23, 2016 
competing $\mathrm{N}-\mathrm{H}$ dissociation reaction would deplete the dative adsorbate.

Among the tertiary amines, trimethylamine (TMA) adsorption on $\mathrm{Si}(100)$ has been studied in some detail. This includes theoretical studies into the activation energy of $\mathrm{N}-\mathrm{C}$ bond dissociation, ${ }^{23}$ XPS studies of the dissociation products at elevated temperature, ${ }^{26}$ thermal desorption following TMA dosed at $100 \mathrm{~K}^{29}$ and other aspects of the adsorption process. $^{30,31}$ To summarize this work, at room temperature TMA mostly forms a stable datively bonded species, and a minor channel leads to N-C cleavage. Similar to TMA, triethylamine (TEA) is also an interesting tertiary amine capable of forming a stable datively bonded species on silicon. XPS studies of TEA adsorption on $\mathrm{Si}(100)-2 \times 1$ also point to the behavior that is very similar to that of TMA: the formation of a datively bonded adduct and a dissociated adduct through scission of $\mathrm{N}-\mathrm{C}$ bond. ${ }^{32}$ In addition, a scanning tunneling microscopy study confirmed that at low coverage a datively bonded TEA produces the $c(4 \times 2)$ templating of the silicon surface; at a nearly saturated coverage, datively bonded TEA molecules self-organize into $c(4 \times 2)$ domains, with an occupancy of one molecule per two dimers, and exhibit a ternary symmetry. ${ }^{32}$ Thus, these experimental and computational studies confirm the potential implications of using tertiary amines as templates for patterning $\mathrm{Si}(100)-2 \times 1$ surfaces.

Of course, besides patterning and altering the properties of silicon or germanium surfaces, the amines can also serve as anchors to introduce new functionalities to these substrates. Bifunctional molecules, and amines in particular, have attracted considerable interest due to their potential to serve as a platform for further surface functionalization. ${ }^{1}$ Toward this aim, various nitrogen-containing bifunctional molecules, including pyrimidine, ${ }^{14}$ tetramethylethylenediamine, ${ }^{33}$ phenylenediamine, ${ }^{15}$ and ethylenediamine, ${ }^{34}$ have been studied on both $\mathrm{Ge}(100)$ and $\mathrm{Si}(100)$ surfaces. For example, Yoshinobu and coworkers ${ }^{33}$ have demonstrated that a dual tertiary amine can link between two down-buckled silicon atoms of two neighboring dimers of the $\mathrm{Si}(100) 2 \times 1$ surface. In order to create a template that retains the well-defined patterning capabilities of TMA and at the same time provides a reactive remaining functional group available for further surface modifications, the choice of amine for such a modification has to be based on a constrained molecule that would only be expected to create a single anchored adsorbate with a fully retained additional chemical functionality. In the work presented here, these tasks are addressed by utilizing a bicyclic cage as a means for both retaining a single possibility for the formation of surface adsorbate and retaining the well-defined chemical functionality. The adsorption and stability of triethylenediamine (TEDA), also known as 1,4-diazabicyclo[2.2.2] octane (DABCO), on $\mathrm{Si}(100)$ was investigated in order to understand its dative bonding and to follow its thermal dissociation pathways. Triethylenediamine has not been previously studied on elemental semiconductor surfaces, but its adsorption behavior has been known on carbon matrices ${ }^{35,36}$ and on aluminum oxides. ${ }^{37-39}$ The initial expectation is that triethylenediamine could form a stable dative bond on $\operatorname{Si}(100)-2 \times 1$ and still have one remaining nitrogen available for further functionalization.

\section{EXPERIMENTAL AND COMPUTATIONAL METHODS}

Fourier-transform infrared (FT-IR) experiments were performed at the University of Delaware in an ultrahigh vacuum
(UHV) chamber with a base pressure below $1 \times 10^{-9}$ Torr. Attached to the chamber was an ion gun for cleaning the sample surface, and an unshielded mass spectrometer (SRS 200 RGA) was used to confirm the purity of the compounds dosed into the chamber. The chamber is equipped for Auger electron spectroscopy (AES) and coupled to an infrared spectrometer (Nicolet, Magna 560) with an external mercury cadmium telluride (MCT) detector cooled with liquid nitrogen. The spectrometer was set up in a multiple internal reflection (MIR) mode for the experiments presented here.

The silicon (100) sample used for the FT-IR experiments was a dual-side polished silicon crystal with $45^{\circ}$ beveled edges (25 mm $\times 20 \mathrm{~mm} \times 1 \mathrm{~mm}$, Harrick Scientific Corporation). The sample was mounted on a manipulator capable of heating the sample to $1100 \mathrm{~K}$ and cooling to approximately $100 \mathrm{~K}$ with liquid nitrogen. The surface was cleaned by sputtering with argon (99.9999\%, Matheson, no further purification), followed by $20 \mathrm{~min}$ of annealing at $\sim 1050 \mathrm{~K}$; the cleanliness of the surface was confirmed with AES. Triethylenediamine (98\%, Aldrich, CAS Number 280-57-9) is solid at room temperature, but its vapor pressure is sufficient for dosing in vacuum. The compound is very hygroscopic, but any water adsorbed during transfer can be removed with moderate heating in vacuum. The purity of the vapor was confirmed in situ by mass spectrometry.

The FT-IR spectra were collected using 512 scans per spectrum at a resolution of $4 \mathrm{~cm}^{-1}$. The compound was introduced into the chamber via a leak valve following the acquisition of a background spectrum. After the desired exposure was reached, the chamber was evacuated to base pressure, and a sample spectrum was collected. When annealing of the surface to a higher temperature was required, the sample spectrum was taken after the crystal was allowed to cool to the temperature of the background. All exposures are reported in units of Langmuir ( $1 \mathrm{~L}=10^{-6}$ Torr $\left.\cdot \mathrm{s}\right)$.

Temperature-programmed desorption (TPD) experiments were performed in a separate UHV chamber with a base pressure below $1 \times 10^{-9}$ Torr. This chamber is equipped with a differentially pumped mass spectrometer (SRS 200 RGA) to characterize the molecular fragments that evolve from the surface during TPD. This instrument is also equipped with an ion gun for surface sputtering and an Auger spectrometer for confirming the cleanliness of the surface following the preparation procedure. After triethylenediamine was leaked into the chamber via the leak valve to achieve the desired exposure, the crystal was placed in front of the mass spectrometer, and the temperature was increased linearly at a rate of approximately $2 \mathrm{~K} / \mathrm{s}$ using a Eurotherm controller.

In-situ XPS and near-edge X-ray adsorption spectroscopy (NEXAFS) experiments were performed on the soft X-ray (SXR) beamline at the Australian Synchrotron. ${ }^{40}$ Silicon (100) samples were $0.04-0.06 \mathrm{Ohm} \cdot \mathrm{cm}$ Sb-doped (Virginia Semiconductor Inc.) that were degassed at $\sim 550{ }^{\circ} \mathrm{C}$ overnight before the first use. Atomically clean and flat $\mathrm{Si}(100)$ surfaces were prepared by flash annealing to $\sim 1200{ }^{\circ} \mathrm{C}(10 \mathrm{~A}, 6 \mathrm{~V}$ direct current) for $10 \mathrm{~s}$ with a programmed cool down. Low-energy electron diffraction (LEED) was used to confirm the atomic reconstruction of the surface. High-resolution Si $2 p$ spectra recorded over a period of an hour showed only a slight reduction in the intensity of the low binding energy peak associated with the up-buckled surface dimers, ${ }^{41}$ confirming only very low levels of adsorption from contaminant species from the chamber background. Triethylenediamine preparation and deposition were performed in the same manner described 
above. Clean $\mathrm{Si}(100)$ surfaces were prepared via flash anneal prior to each triethylenediamine dose, with the sample being allowed to cool for $10 \mathrm{~min}$ between flashing and triethylenediamine exposure. The sample temperature was confirmed to be lower than $80{ }^{\circ} \mathrm{C}$ at the time of dosing by a thermocouple mounted on the sample holder (but not in direct contact with the silicon). The sample temperature during annealing was recorded indirectly by monitoring the sample heating power. We estimate temperature using a linear extrapolation from the heating power $(5.2 \mathrm{~W})$ where the sample exhibited a barely visible dull cherry red glow, to which we assigned a temperature of $\sim 525{ }^{\circ} \mathrm{C}^{42}$ Once dosed, the samples were immediately transferred under UHV to the adjacent analysis chamber for XPS or NEXAFS measurements. XPS measurements were acquired with a photon energy of $440 \mathrm{eV}$ to maximize sensitivity to nitrogen and allow both carbon and nitrogen spectra to be acquired without changing the beam energy. For each carbon/nitrogen measurement a $\mathrm{Au}$ (4f) reference spectrum was acquired using a gold reference foil in electrical contact with the sample, which was later used for energy calibration. The CasaXPS software ${ }^{43}$ was used for data processing and peak fitting.

Carbon and nitrogen K-edge NEXAFS spectra were recorded in a partial electron yield (PEY) mode for five angles between normal and grazing angle photon incidence $(90,70,55,40$, and $\left.20^{\circ}\right)$. Normalization was performed using reference scans from a clean $\mathrm{Si}(100)$ surface together with the flux signal from a $50 \%$ transmissive gold grid placed upstream of the sample. ${ }^{44}$

We note that at high photon intensity the triethylenediamine-dosed $\mathrm{Si}(100)$ surface was susceptible to beam-induced changes in surface composition. However, we were able to strongly limit the deleterious effects of the photon beam on our sample by reducing the intensity of the beam. We used XPS monitoring of the carbon and nitrogen 1s spectra during continuous exposure to the beam to confirm that beam-induced changes were negligible at the lowered beam intensity for exposures of less than $10 \mathrm{~min}$. We then ensured all individual measurements could be made in no more than $10 \mathrm{~min}$ and repositioned our beam on the sample between individual measurements, thus ensuring that all acquired data reflect the undamaged state of the organic functionalized surface.

XPS and NEXAFS measurements of the triethylenediaminedosed $\mathrm{Si}(100)$ surface were performed as a function of substrate temperature by annealing the silicon sample via direct current annealing.

Density functional theory (DFT) calculations were conducted using the Gaussian 09 suite of programs. ${ }^{45}$ Calculations were performed with the B3LYP functional ${ }^{46}$ and the 6$311+G(d, p)$ basis set. ${ }^{47}$ A comparison with the B97D/6$311+\mathrm{G}(\mathrm{d}, \mathrm{p})^{48,49}$ approach has also been performed as discussed below, and the resulting energetics is provided in the Supporting Information section. The B3LYP/311+G(d,p) approach has been previously shown to yield reliable results to describe the adsorption chemistry of organic molecules on the $\operatorname{Si}(100)-2 \times 1$ surface. $^{50}$ A comparison with the B97D/6$311+\mathrm{G}(\mathrm{d}, \mathrm{p})$ computation demonstrates the effect of dispersion interactions. The silicon surface is represented using $\mathrm{Si}_{9} \mathrm{H}_{12}$ and $\mathrm{Si}_{15} \mathrm{H}_{16}$ cluster models that describe one and two $\mathrm{Si}-\mathrm{Si}$ dimers, respectively. These clusters were first optimized at the B3LYP/ $6-311+G(d, p)$ level of theory with all atoms allowed to fully relax. Then, the desired adsorbate was added to the cluster model, and the entire structure was reoptimized at the same level of theory. Vibrational frequencies were calculated at the
B3LYP/6-311+G(d,p) level of theory. Predicted binding energies of XPS peaks of nitrogen and carbon were derived from these calculations using the calibration procedure based on Koopmans' theorem described in detail in ref 51.

\section{RESULTS AND DISCUSSION}

III.1. Thermal Desorption Investigation of the Proposed Adsorption and Decomposition Mechanisms for Triethylenediamine on a Clean Si(100)-2 $\times 1$ Surface. In order to understand the key steps of the adsorption and thermal chemistry of TEDA on a clean $\mathrm{Si}(100)-2 \times 1$ surface, thermal desorption experiments were carried out on both monolayer and multilayer samples. Figure 1 summarizes the main observations of these experiments.

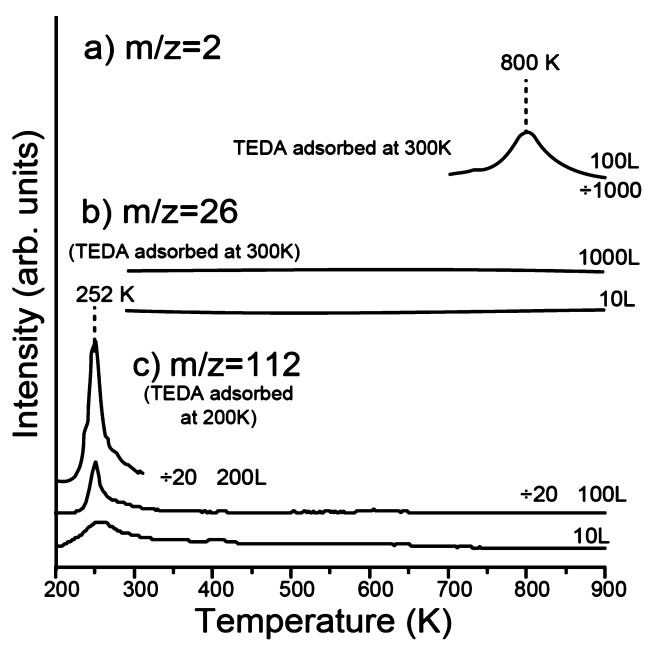

Figure 1. Summary of temperature-programmed desorption studies of triethylenediamine adsorbed on a clean $\mathrm{Si}(100)-2 \times 1$ surface. (a) Desorption of $\mathrm{H}_{2}(\mathrm{~m} / z=2)$ following triethylenediamine adsorption at $300 \mathrm{~K}$. (b) Desorption of ethylene $(\mathrm{m} / z=26)$ following small (10 $\mathrm{L})$ and large $(1000 \mathrm{~L})$ exposures of triethylenediamine at $300 \mathrm{~K}$ showing the absence of ethylene evolution. (c) Molecular desorption profile of multilayers of triethylenediamine condensed at $200 \mathrm{~K}$.

The two main thermal desorption processes observed are molecular desorption $(m / z=112)$ at approximately $250 \mathrm{~K}$ and desorption of molecular hydrogen $(\mathrm{m} / z=2)$ at approximately $800 \mathrm{~K}$. Molecular desorption is only observed for the multilayer samples prepared at $200 \mathrm{~K}$. Hydrogen desorption presumably occurs as a result of TEDA decomposition on the surface. No evidence is found for the desorption of other signature fragments, such as ethylene $(m / z=26)$.

The enthalpy of sublimation measured for triethylenediamine by differential thermal analysis is reported to be $61.9 \mathrm{~kJ} / \mathrm{mol}^{52}$ The experimental data recorded in Figure 1 for molecular desorption around $252 \mathrm{~K}$ yield the corresponding activation energy of $66.7 \mathrm{~kJ} / \mathrm{mol}$ approximately estimated based on the first-order desorption evaluated by Redhead analysis with preexponential factor of $10^{13} \mathrm{~s}^{-1}$. 53 This number is fully consistent with the reported enthalpy of sublimation of triethylenediamine.

Based on the thermal desorption investigation and on the previously reported chemistry of amines on silicon, it is proposed that the adsorption and thermal chemistry processes for TEDA on a clean $\mathrm{Si}(100)-2 \times 1$ surface proceed as outlined in Scheme 1. 
Scheme 1. Reaction Pathways of Triethylenediamine Transformations on a Clean $\mathrm{Si}(100)-2 \times 1$ Surface $^{a}$

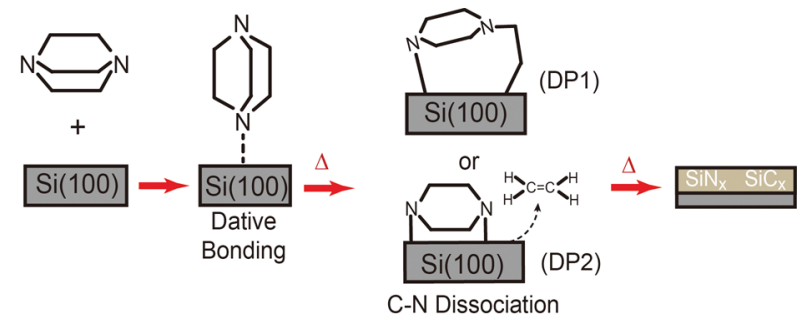

${ }^{a} \mathrm{DP} 1$ represents the structure yielded by dissociating a single $\mathrm{C}-\mathrm{N}$ bond; DP2 represents the structure obtained following double $\mathrm{C}-\mathrm{N}$ dissociation and ethylene elimination.

According to the proposed mechanism, we expect that the triethylenediamine molecule would absorb to the clean silicon surface by forming a dative bond. At elevated temperatures, this datively bonded species would undergo dissociation, as illustrated for the $\mathrm{C}-\mathrm{N}$ bond in Scheme 1. Eventually, the molecule would completely break up and form carbide and nitride species on the surface. In order to test this hypothesis, we need to (1) demonstrate that the initial adsorption of the triethylenediamine molecule results in a datively bonded species, (2) that $\mathrm{C}-\mathrm{N}$ dissociation is associated with the start of molecular decomposition, and (3) that at elevated temperatures no processes take place other than the formation of surface silicon carbide and nitride species and the desorption of hydrogen. Infrared spectroscopy should be the most appropriate surface analytical technique to provide the information about the mechanism of surface decomposition. A pertinent question to be addressed is whether the decomposition of the TEDA molecule leads to the formation of $\mathrm{Si}-\mathrm{H}$ bonds.

III.2. Infrared Investigation of the Adsorption and Thermal Decomposition of Triethylenediamine on a Clean Si(100)-2 $\times 1$ Surface. Adsorption and thermal transformations of triethylenediamine were followed by infrared spectroscopy, as summarized in Figure 2. Spectra $a-d$ in this figure describe the adsorption of a small amount $(0.5 \mathrm{~L}$ dose, submonolayer as will be demonstrated later by XPS) of triethylenediamine on a clean $\mathrm{Si}(100)-2 \times 1$ surface at $130 \mathrm{~K}$ followed by brief annealing to the temperatures indicated. With $0.5 \mathrm{~L}$ of triethylenediamine dosed onto the clean $\mathrm{Si}(100)$ at 130 $\mathrm{K}$, the surface was briefly heated to different temperatures up to $200 \mathrm{~K}$, and the infrared spectra after each annealing were collected after the surface cooled back to $130 \mathrm{~K}$. All these spectra contain the expected absorption bands $\left(\nu_{\mathrm{C}-\mathrm{H}}=2869.6\right.$ $\mathrm{cm}^{-1}, 2937.3 \mathrm{~cm}^{-1} ; \delta_{\mathrm{C}-\mathrm{H}}=1465 \mathrm{~cm}^{-1}, 1315.4 \mathrm{~cm}^{-1}$ ) corresponding to the molecular triethylenediamine. These assignments are fully supported by the DFT investigation with the predicted spectra of a molecular and datively bonded triethylenediamine presented underneath the experimental data. Despite some subtle differences between the two predicted spectra, as expected, they describe very similar species that cannot be distinguished based solely on this set of studies. However, it is interesting to contrast the cryogenic temperature investigation with the room-temperature adsorption shown in spectra $\mathrm{e}-\mathrm{g}$. The spectrum collected following the triethylenediamine dose at room temperature (where no multilayers can be adsorbed) looks very similar to those collected at cryogenic temperatures. Although the intensity of the absorption features drops noticeably, all the expected features are the same as those in the low-temperature spectra.

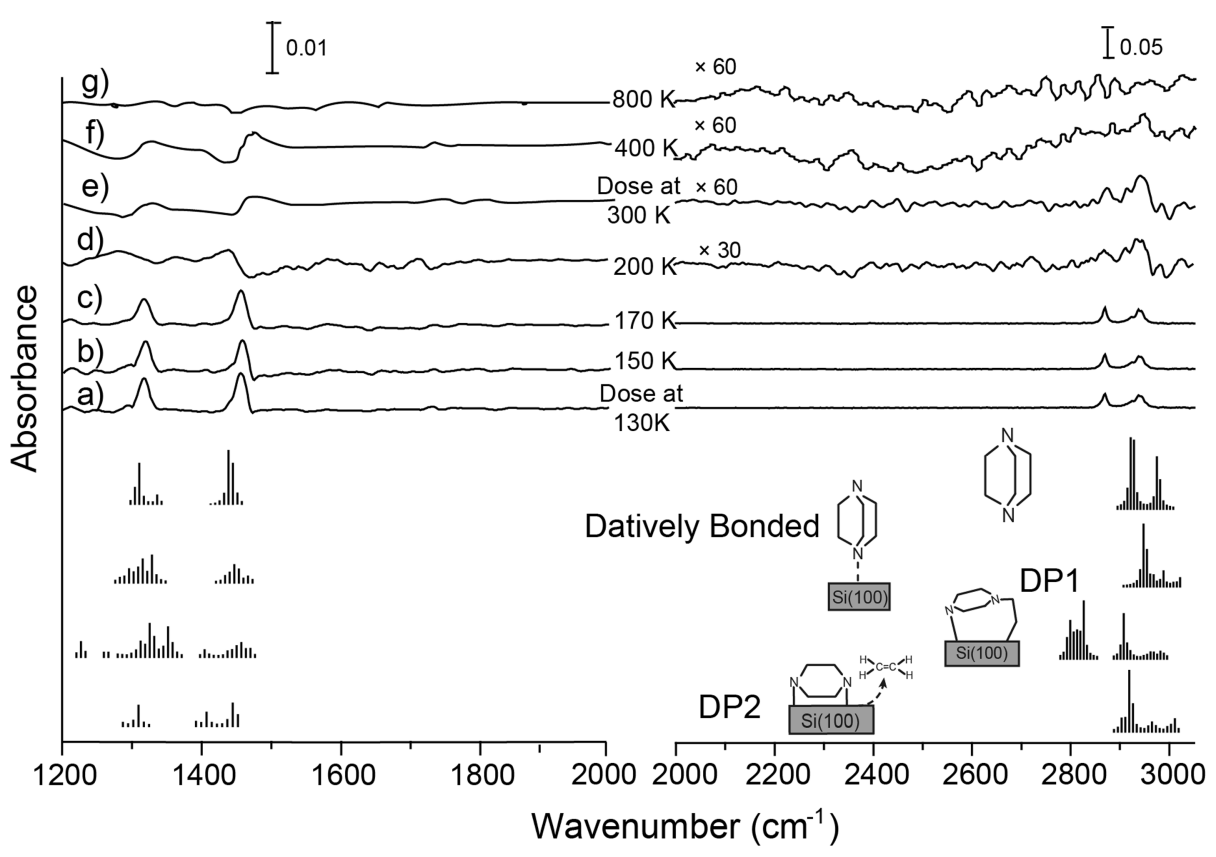

Figure 2. Summary of the infrared spectroscopy investigations of the adsorption and thermal transformations of triethylenediamine on a clean $\mathrm{Si}(100)-2 \times 1$ surface. (a), (b), (c), and (d) represent the spectra of the surface exposed with $0.5 \mathrm{~L}$ of triethylenediamine at $130 \mathrm{~K}$ and then consecutively annealed to 150,170 , and $200 \mathrm{~K}$. The background used was the spectrum collected from a clean $\mathrm{Si}(100)$ surface at $130 \mathrm{~K}$. (e), (f), and (g) represent the spectra of the surface exposed to $1000 \mathrm{~L}$ of triethylenediamine at $300 \mathrm{~K}$ and then consecutively annealed to between 400 and 800 $\mathrm{K}$. The background used was the spectrum collected from the clean $\mathrm{Si}(100)$ surface at $300 \mathrm{~K}$. Shown underneath the experimental spectra are the vibrational frequencies predicted by DFT of molecular triethylenediamine, the datively bonded adsorbate, and the dissociated adsorbates DP1 and DP2. These calculations were performed using the B3LYP/6-311+G(d,p) approach. 
Annealing to $400 \mathrm{~K}$ does not affect the spectra too much; however, a noticeable absorption around $2800 \mathrm{~cm}^{-1}$ is now observed. According to the thermal desorption studies described above, no products desorb from the surface within this temperature range, and thus the spectral changes can only be caused by surface reactions. The absence of $\mathrm{Si}-\mathrm{H}$ vibrations (that are normally of substantially higher intensity than $\mathrm{C}-\mathrm{H}$ bands) demonstrates that hydrogen transfer from the molecule to the surface is not a major decomposition pathway for triethylenediamine on $\mathrm{Si}(100)$. The two possible surface reaction pathways suggested in Scheme 1 lead to the formation of two very different species, whose infrared spectra are also predicted using DFT and displayed in Figure 2. Only one of these species, namely, the $\mathrm{C}-\mathrm{N}$ dissociation structure DP1, exhibits substantial absorption in the spectral region between 2700 and $2900 \mathrm{~cm}^{-1}$. This suggests that the reaction pathway leading to structure DP1 is worth investigating further. This is also consistent with the fact that the ethylene elimination caused by a double dissociation of $\mathrm{C}-\mathrm{N}$ bonds is not observed in thermal desorption. It is expected that if ethylene is formed on a clean $\mathrm{Si}(100)-2 \times 1$ surface it would remain bound until approximately $600 \mathrm{~K}^{54,55}$ depending on the neighboring surface species. In fact, desorption temperatures as high as $700 \mathrm{~K}$ were reported for ethylene desorption from ethylene adsorbed as well as iodoethane adsorbed on $\mathrm{Si}(100)$ surfaces. ${ }^{55,56}$ However, the TPD studies presented in Figure 1 do not record any ethylene desorption even at these high temperatures.

Annealing the surface to $800 \mathrm{~K}$, shown in spectrum $\mathrm{g}$ of Figure 2, results in a featureless spectrum, consistent with elimination of hydrogen and dissociation of hydrogencontaining species, which is also consistent with the formation of poorly defined surface carbide $\left(\mathrm{SiC}_{x}\right)$ and nitride $\left(\mathrm{SiN}_{x}\right)$ species.

Thus, infrared investigations suggest that the nature of adsorbed species of triethylenediamine does not change substantially between 130 and $300 \mathrm{~K}$ and that thermal decomposition starts around $400 \mathrm{~K}$; however, spectral similarity of several proposed adsorption species prevents a more precise identification of the decomposition products.

III.3. XPS Analysis of Thermal Chemistry of Triethylenediamine on a Clean $\mathrm{Si}(100)-2 \times 1$ Surface. To investigate the nature of triethylenediamine adsorbed on a clean $\mathrm{Si}(100)-2 \times 1$ surface, a set of XPS studies were performed as a function of surface temperature, as shown in Figure $4 a$ and $4 b$ corresponding to $\mathrm{C} 1 \mathrm{~s}$ and $\mathrm{N} 1 \mathrm{~s}$ spectral regions. As was mentioned above in the infrared spectroscopy studies, the observed spectroscopic signatures involving carbon atoms are very similar in the adsorbed species and in all the models considered. Thus, for the characterization of triethylenediamine, the $\mathrm{N}$ 1s spectral region is expected to be much more informative.

Figure $4 \mathrm{a}$ and $4 \mathrm{~b}$ show synchrotron-based XPS spectra collected from samples prepared in situ as described in the Experimental section. The bottom trace corresponds to the exposure of $0.9 \mathrm{~L}$ of triethylenediamine dosed on a silicon surface at room temperature. Following brief annealing to the temperatures indicated, all the other traces are obtained. According to the coverage profile in Figure 3, the dose of $0.9 \mathrm{~L}$ corresponds to approximately $60 \%$ of the monolayer, and thus this set of experiments allows for investigation of the behavior of individual triethylenediamine molecules adsorbed on a clean $\mathrm{Si}(100)-2 \times 1$ surface. By comparing the experimental spectra collected for room-temperature adsorption, it is clear that the

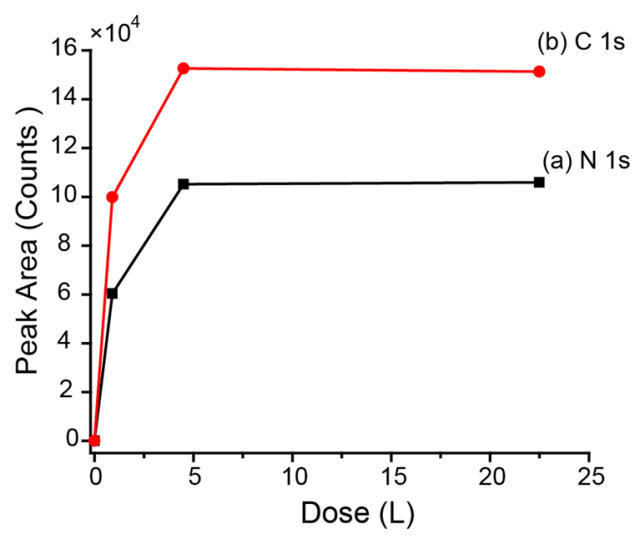

Figure 3. Surface coverage profile as determined via XPS peak areas for (a) $\mathrm{N} 1 \mathrm{~s}$ and (b) $\mathrm{C} 1 \mathrm{~s}$ with the exposure of $0.9,4.5$, and $22.5 \mathrm{~L}$ of triethylenediamine at room temperature.

spectra at different exposures are very similar. The main features observed correspond to the positions expected for free and datively bonded nitrogen atoms. These assignments are supported by the DFT modeling provided in Figure 2 and are consistent with the previous observations of multilayers of amines with $\mathrm{N} 1 \mathrm{~s}$ features at $400.2^{57}$ and $400.6 \mathrm{eV}^{58}$ and datively bonded amines with the same features at $402.2^{28}$ and $401.2 \mathrm{eV}^{58}$ The high binding energy at $401.1 \mathrm{eV}$ from experimental measurements lines up well with the DFTpredicted $401.3 \mathrm{eV}$ representing the nitrogen atom datively bonded with the silicon atom. The other peak standing for the free nitrogen has a $0.5 \mathrm{eV}$ higher shift than the DFT predicted peak. This probably resulted from the complex environment around the free nitrogen atom. If the free nitrogen is reactive to bind with some unavoidable species in chamber, such as $\mathrm{CO}$ and $\mathrm{H}_{2}$, the chemical environment may be changed. For example, it has been proved that the nitrogen in structures like tetraalkylammonium salts will have a higher binding energy shift. $^{26,59}$ Also, different basis sets, functional methods, and correction methods will influence the natural bond orbital (NBO) analysis used for the computational models.

However, one immediate question arising from these assignments is why these two features differ in intensity. It is expected that a datively bonded structure would result in one free nitrogen atom and another one on the same molecule bonded to surface silicon, thus resulting in two features of equal intensity. However, this expectation is based on the binding of an individual molecule to a perfect $\mathrm{Si}(100)-2 \times 1$ surface followed by the corresponding charge redistribution between two nitrogen atoms within the same adsorbate. However, if the adsorption occurs at neighboring surface sites or at surface sites near impurities present in small quantities, this charge redistribution may be very different. To illustrate this point, two additional cluster models, representing a surface-bound hydrogen atom or a hydroxyl group (expected surface impurities on silicon), were investigated. The results of this comparison are presented in Figure $4 \mathrm{a}$ and $4 \mathrm{~b}$ for these models that can be briefly described as $\mathrm{H}-\mathrm{Si}-\mathrm{Si}-\mathrm{TEDA}$ and $\mathrm{OH}-\mathrm{Si}-$ $\mathrm{Si}-\mathrm{TEDA}$. It is very clear that the formation of a datively bonded species by triethylenediamine on a silicon surface that has $\mathrm{H}$ - or HO-neighboring species not only moves the electronic environment of the two nitrogen atoms for them to appear closer to each other in the XPS spectrum but also shifts the energy toward substantially lower binding energies, which is consistent with the results in Figure $4 \mathrm{~b}$. Furthermore, 

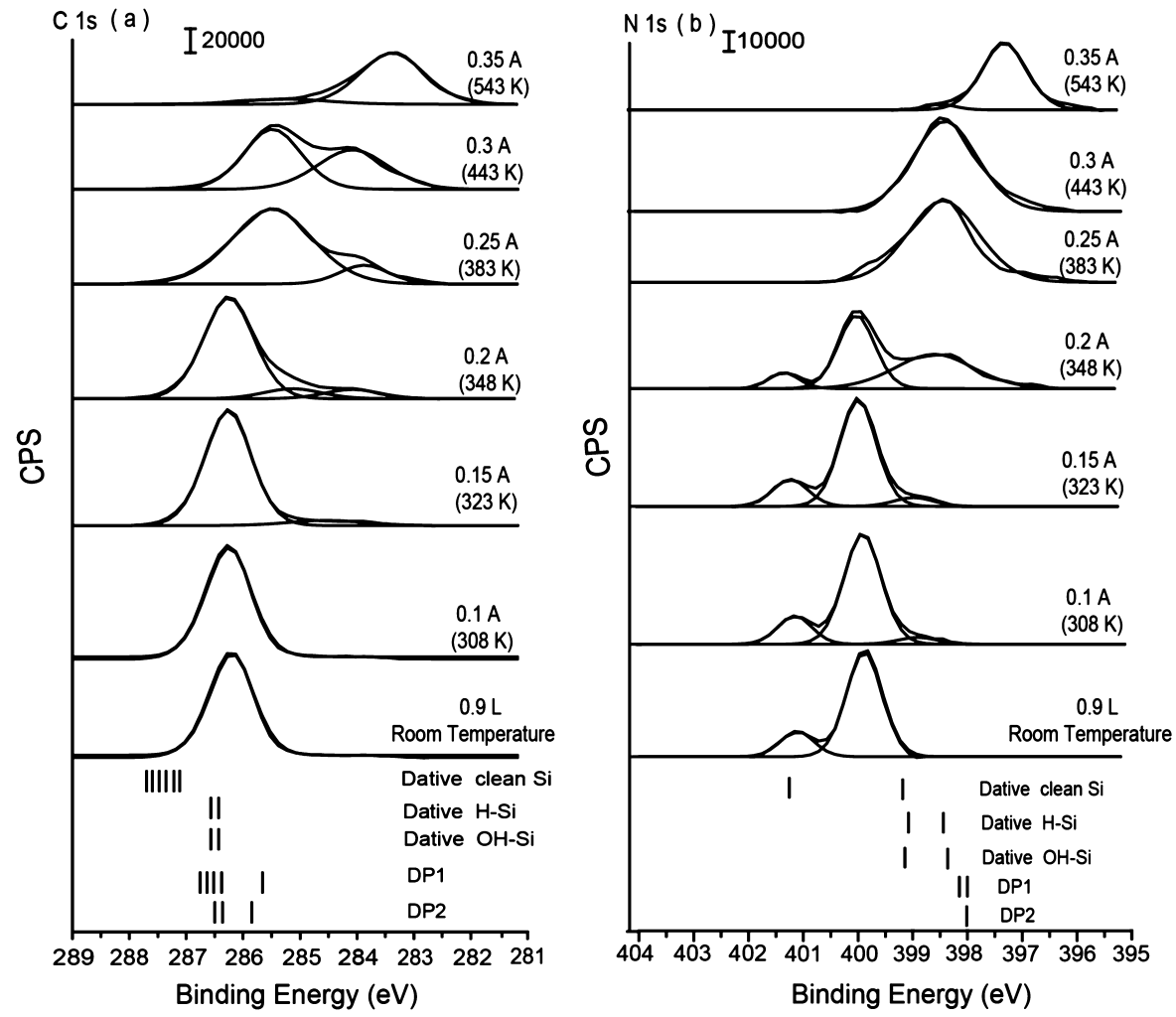

Figure 4. In situ XPS (a) C 1s spectra and (b) N 1s spectra collected with $0.9 \mathrm{~L}$ of triethylenediamine on the $\mathrm{Si}(100)$ surface at room temperature, followed by elevating the temperature with changing the current. Note that the temperatures are converted from heating power using a linear extrapolation from $5.2 \mathrm{~W} / 800 \mathrm{~K}$; this leads to an underestimate in the temperature that is most significant at the higher temperatures. DFTpredicted $\mathrm{C} 1 \mathrm{~s}$ and $\mathrm{N} 1 \mathrm{~s}$ binding energies using different reaction models are shown below the experimental data.

the $\mathrm{C}$ 1s spectra observed in Figure 4a gave us more consistent results in the comparison between $\mathrm{H}-\mathrm{Si}-\mathrm{Si}-\mathrm{TEDA}$ and $\mathrm{OH}-$ $\mathrm{Si}-\mathrm{Si}-\mathrm{TEDA}$ modeling binding energies with experimental binding energies. Before we built up $\mathrm{H}-\mathrm{Si}-\mathrm{Si}-\mathrm{TEDA}$ and $\mathrm{OH}-\mathrm{Si}-\mathrm{Si}-\mathrm{TEDA}$ models, we found the experimental results had a lower shift than DFT dative bonding species on a clean $\mathrm{Si}(100)$ surface.

The next question that can be addressed with the help of XPS is thermal transformations of datively bonded triethylenediamine. As the surface with triethylenediamine adsorbed at room temperature is briefly annealed to the temperatures indicated in Figure 4b, the peak around $398 \mathrm{eV}$, which is barely visible at room temperature, becomes very pronounced, while the overall intensity of the $\mathrm{N} 1 \mathrm{~s}$ features does not change. This peak corresponds to the thermal $\mathrm{C}-\mathrm{N}$ dissociation process proposed above, and the XPS signature is consistent with the predicted positions for either one of the two proposed structures described in Scheme 1. This approach can also be used to interpret the C 1s spectra in Figure 4a. DFT-predicted DP1 and DP2 carbon binding energies both gave a lower peak around $285.6 \mathrm{eV}$. Similar to the N 1s observation, when the surface was heated to a certain temperature with 0.2 A current, a new peak became intense at $284.0 \mathrm{eV}$. Although the experimental peak position is not fully consistent with the DFT-predicted position for dissociation products, as we mentioned in the previous paragraph, this shift between experiments and modeling could be explained if we take surface defects and minority species such as $\mathrm{H}-\mathrm{Si}-\mathrm{Si}$ and $\mathrm{OH}-\mathrm{Si}-\mathrm{Si}$ into consideration. However, since ethylene desorption was not observed, it is most likely that the structure denoted as DP1 is dominant on a surface at this temperature. In general, given that $\mathrm{C}-\mathrm{N}$ dissociation of a datively bonded triethylenediamine is expected to provide a structure of the type of DP1 as a starting point and given that this structure has the second nitrogen atom directed away from the surface, elimination of ethylene to form structure DP2 does not seem likely, unless it is a concerted process with simultaneous breaking of both $\mathrm{C}-\mathrm{N}$ bonds in triethylenediamine. However, again based on the observation of the datively bonded structure and infrared and TPD studies described above, this pathway is not observed by any of the approaches reported here.

Finally, again consistent with the rest of the investigations, when the annealing temperature is increased substantially, $\mathrm{N}$ 1s and $\mathrm{C} 1 \mathrm{~s}$ both shift to a much lower binding energy, which corresponds to the formation of surface silicon nitride ${ }^{60}$ and silicon carbide. ${ }^{61}$

Thus, the XPS results confirm that triethylenediamine forms a datively bonded species at room temperature within a monolayer on a $\operatorname{Si}(100)-2 \times 1$ surface. This adsorbate undergoes $\mathrm{C}-\mathrm{N}$ dissociation at elevated temperatures to yield predominantly the DP1 species. Finally, at temperatures around $800 \mathrm{~K}$, surface nitride species are formed.

III.4. NEXAFS Analysis of Room-Temperature Adsorption of Triethylenediamine on a Clean Si(100)- $2 \times 1$ Surface: Geometry of the Adsorbate. Figure 5 shows the summary of NEXAFS measurements following the dose of 0.9 $\mathrm{L}$ of triethylenediamine onto the $\mathrm{Si}(100)$ surface at room temperature. There is a clear peak present at $288.0 \mathrm{eV}$, just below the ionization potential, that can be attributed to $\mathrm{C}-\mathrm{H}$ $\sigma^{*}$ resonance states. ${ }^{62}$ This feature shows clear dichroism with the intensity of the peak exhibiting a maximum at the normal incident beam angle, consistent with our expectation for a 


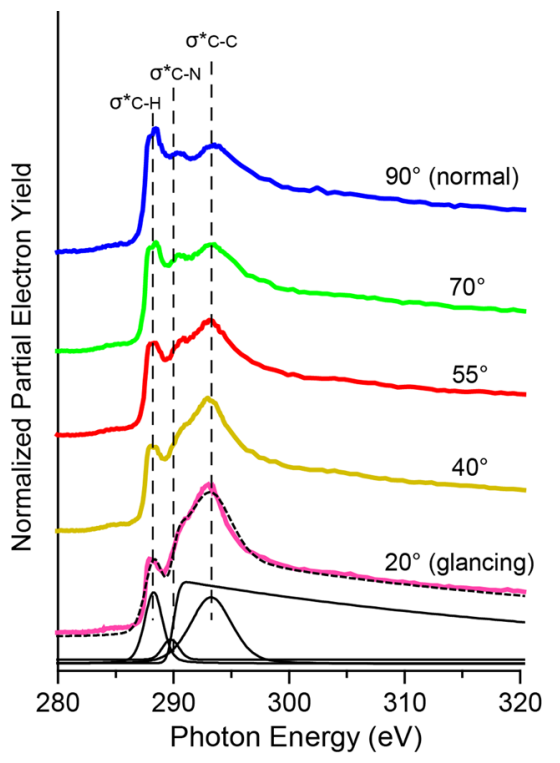

Figure 5. Angle-dependent carbon K-edge NEXAFS spectra of the $\mathrm{Si}(100)$ surface exposed to $0.9 \mathrm{~L}$ of TEDA at room temperature.

datively bonded triethylenediamine structure that the $\mathrm{C}-\mathrm{H}$ bonds lie somewhat in the plane of the surface. Fitting the variation in intensity of this peak to the incident photon angle by the procedure described in detail by Stöhr ${ }^{63}$ produces an angle of $61 \pm 1^{\circ}$ (Figure S2). There is an additional pair of peaks above the ionization potential at 290.3 and $293.9 \mathrm{eV}$. The energetic location of these peaks suggests they are associated with $\sigma^{*}$ resonances. The peak at $293.9 \mathrm{eV}$ shows an increasing trend in intensity at the grazing-incident angle, consistent with a vertically orientated bond, and in this case a fit produces an angle of $21 \pm 1^{\circ}$ with respect to surface normal. This peak clearly corresponds to the $\mathrm{C}-\mathrm{C}$ bond in the structure of $\mathrm{CH}_{2}-\mathrm{CH}_{2}-$ of the datively bound molecule, indicating that the structure of $-\mathrm{C}-\mathrm{C}-$ is orientated nearly normal to the surface. The feature at $290.3 \mathrm{eV}$ corresponds to the $\sigma^{*}(\mathrm{C}-\mathrm{N})$ resonance. ${ }^{64,65}$ However, fitting the angular dependence of the intensity of this feature is unreliable since the intensity depends drastically on the fit of the ionization potential step.

It can be noted that the overall balance of the thermal process is consistent with the surface coverage recorded by AES and summarized in Table 1 . These data suggest that there is no significant decrease in carbon-to-nitrogen ratio with the increasing temperature. In agreement with what was observed from TPD results, if the dissociation with temperature increase happens with the formation of ethylene, we were supposed to observe the ethylene desorption at around $600 \mathrm{~K}$ and the

Table 1. Elemental Concentration Data Calculated for Silicon, Carbon, and Nitrogen from AES Spectra at Several Temperatures $^{a}$

$\begin{array}{cc} & \mathrm{C} / \mathrm{N} \\ 300 \mathrm{~K} & 3.5 \pm 0.1 \\ 400 \mathrm{~K} & 2.7 \pm 0.2 \\ 500 \mathrm{~K} & 2.9 \pm 0.2 \\ 600 \mathrm{~K} & 2.9 \pm 0.3 \\ 700 \mathrm{~K} & 2.6 \pm 0.3\end{array}$

${ }^{a}$ The values for $\mathrm{C} / \mathrm{N}$ were calculated and applied with sensitivity factors. decrease in $\mathrm{C} / \mathrm{N}$ ratio. According to the lack of the expected results from ethylene formation, we could assume that the dissociation pathway is likely to be accompanied by only one $\mathrm{C}-\mathrm{N}$ cleavage, as shown in Scheme 1.

III.5. DFT Explanation of the Adsorption and Decomposition of Triethylenediamine on a Clean Si(100)-2 $\times 1$ Surface. In order to explore the thermodynamics of the thermal decomposition of triethylenediamine on $\mathrm{Si}(100)$, DFT calculations were performed for the proposed surface structures. The adsorption and decomposition of a single triethylenediamine molecule were modeled on a two dimer $\mathrm{Si}(100)$ cluster $\left(\mathrm{Si}_{15} \mathrm{H}_{16}\right)$. The objective of these calculations is to compare the stability of three plausible structures as shown in Figure 6. These are (1) a stand-up dative

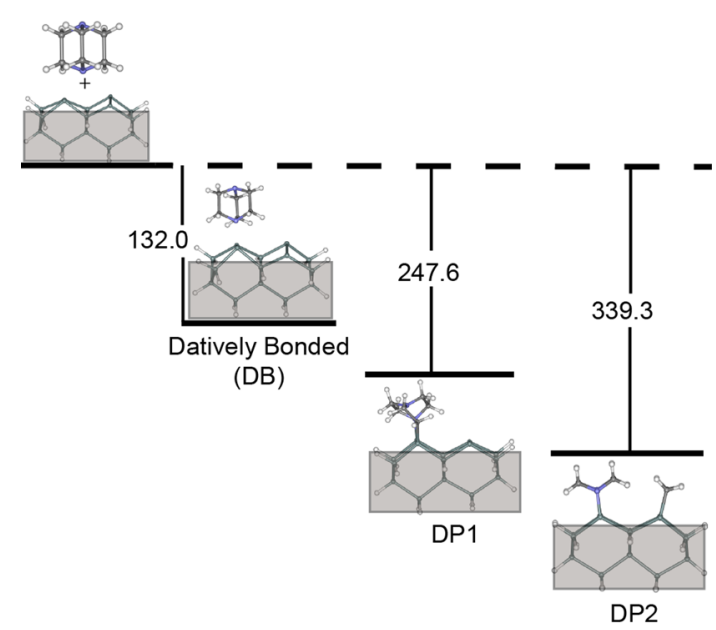

Figure 6. DFT calculations using the B3LYP functional and the 6$311+\mathrm{G}(\mathrm{d}, \mathrm{p})$ basis set. The datively bonded complex is $-132.0 \mathrm{~kJ} / \mathrm{mol}$ more stable compared to the gas-phase triethylenediamine. Dissociation product DP1 and dissociation product DP2 both have much higher stability at $-247.6 \mathrm{~kJ} / \mathrm{mol}$ and $-339.3 \mathrm{~kJ} / \mathrm{mol}$, relative to the gas-phase species.

bonding structure, (2) a structure labeled DP1 in which one $\mathrm{C}-\mathrm{N}$ bond dissociation has occurred and the carbon atom binds a silicon atom in the same dimer, and (3) a structure labeled DP2 in which two $\mathrm{C}-\mathrm{N}$ bond dissociations have occurred such that a separate ethylene fragment has formed that binds in a $[2+2]$ fashion to an adjacent dimer. Of these three structures, DP2 is the most stable. However, it requires the datively bonded complex to either undergo some complex concerted process of ethylene elimination, which was ruled out by experimental TPD and infrared studies, or be initially structured like DP1 followed by dissociation of the bond between the second nitrogen and a carbon. However, this geometry is extremely unfavorable for such a process, as the second nitrogen atom is directed away from the surface and in fact is located at the apex of the structure that is the furthest away, making this transformation extremely unlikely despite the ultimate thermodynamic stability predicted by DFT. Therefore, the calculation results agree with our experimental data. First, at room temperature or lower, datively bonded species could be formed on a clean $\mathrm{Si}(100)$ surface. Second, with increasing temperature, dissociation reactions can happen, provided the energy barriers are overcome. The fact that ethylene products are not observed experimentally suggests that the surface product of the type of DP1 is formed following $\mathrm{C}-\mathrm{N}$ dissociation. The expectation of the $\mathrm{C}-\mathrm{N}$ dissociation is fully 
consistent with the observation previously reported by Hamers that a TMA molecule would form a very stable dative-bond monolayer at room temperature. ${ }^{26}$ In fact, our own calculations for a TEDA- $\mathrm{Si}_{15} \mathrm{H}_{16}$ datively bonded complex suggest that compared to the analogous structure formed by TMA triethylenediamine is actually more stable on this surface $(-132.0 \mathrm{~kJ} / \mathrm{mol}$ for triethylenediamine compared to $-120 \mathrm{~kJ} /$ mol for TMA). ${ }^{26}$ Thus, triethylenediamine is able to form a stable datively bonded structure on a $\mathrm{Si}(100)$ surface with a nitrogen atom available for further functionalization. The Supporting Information (Figure S1) also presents the summary of the computational description of the same species at the B97D/6-311+G(d,p) level of theory to account for the effects of dispersion interactions. These results are fully consistent with those obtained using B3LYP/6-311+G(d,p).

\section{CONCLUSIONS}

The reaction behavior of triethylenediamine on the $\operatorname{Si}(100)$ surface has been investigated. It is found that a datively bonded TEDA-Si-Si complex forms on the surface at room temperature as well as at cryogenic temperature with low exposure. Infrared spectroscopy and NEXAFS have confirmed the vibrational signature and orientation of triethylenediamine on this surface. Based on the XPS and IR results, heating above $400 \mathrm{~K}$ leads to $\mathrm{C}-\mathrm{N}$ dissociation and ultimately the formation of surface nitride and carbide species; however, no other products evolve from the surface except for $\mathrm{H}_{2}$. Thus, consistent with the DFT investigation, a stable and welldefined surface species is formed at room temperature upon triethylenediamine adsorption on a clean $\mathrm{Si}(100)$ surface with a nitrogen atom in the resulting structure available for further functionalization.

\section{ASSOCIATED CONTENT}

\section{S Supporting Information}

The Supporting Information is available free of charge on the ACS Publications website at DOI: 10.1021/acs.jpcc.6b10485.

Computational investigation with B97D functional and intensity of selected NEXAFS features plotted against the incident beam angle and complete references 34 and 45 (PDF)

\section{AUTHOR INFORMATION}

\section{Corresponding Author}

*Tel.: (302) 831-1969. Fax: (302) 831-6335. E-mail: andrewt@ udel.edu.

\section{ORCID ${ }^{\circ}$}

Andrew Teplyakov: 0000-0002-6646-3310

\section{Notes}

The authors declare no competing financial interest.

\section{ACKNOWLEDGMENTS}

Acknowledgment is made to the donors of the Petroleum Research Fund, administered by the American Chemical Society, for partial support of this research. This work was also supported by the National Science Foundation (CHE 1057374) and the Engineering and Physical Sciences Research Council (EP/L002140/1). O.W. acknowledges the support of the Australian Research Council (ARC) Centre of Excellence for Quantum Computation and Communication Technology (project number CE110001027).

\section{REFERENCES}

(1) Teplyakov, A. V.; Bent, S. F. Semiconductor Surface Functionalization for Advances in Electronics, Energy Conversion, and Dynamic Systems. J. Vac. Sci. Technol., A 2013, 31, 050810.

(2) Pearce, B. L.; Wilkins, S. J.; Paskova, T.; Ivanisevic, A. A Review of in Situ Surface Functionalization of Gallium Nitride Via Beaker Wet Chemistry. J. Mater. Res. 2015, 30, 2859-2870.

(3) Amsalem, P.; Heimel, G.; Oehzelt, M.; Koch, N. The Interface Electronic Properties of Organic Photovoltaic Cells. J. Electron Spectrosc. Relat. Phenom. 2015, 204, 177-185.

(4) Liu, Z.; Lau, S. P.; Yan, F. Functionalized Graphene and Other Two-Dimensional Materials for Photovoltaic Devices: Device Design and Processing. Chem. Soc. Rev. 2015, 44, 5638-5679.

(5) Jiang, S.; Arguilla, M. Q.; Cultrara, N. D.; Goldberger, J. E. Covalently-Controlled Properties by Design in Group IV Graphane Analogues. Acc. Chem. Res. 2015, 48, 144-151.

(6) Borshchev, O. V.; Ponomarenko, S. A. Self-Assembled Organic Semiconductors for Monolayer Field-Effect Transistors. Polym. Sci., Ser. C 2014, 56, 32-46.

(7) Ahmad, S. Organic Semiconductors for Device Applications: Current Trends and Future Prospects. J. Polym. Eng. 2014, 34, 279338.

(8) Teplyakov, A. V. Influence of Functional Groups in Substituted Aromatic Molecules on the Selection of Reaction Channel in Semiconductor Surface Functionalization. Functionalization of Semiconductor Surfaces; John Wiley \& Sons, Inc.: Hoboken, NJ, 2012.

(9) Wang, G. T.; Mui, C.; Tannaci, J. F.; Filler, M. A.; Musgrave, C. B.; Bent, S. F. Reactions of Cyclic Aliphatic and Aromatic Amines on Ge(100)- $2 \times 1$ and Si(100)-2 $\times$ 1. J. Phys. Chem. B 2003, 107, 49824996.

(10) Tian, F.; Teplyakov, A. V. Silicon Surface Functionalization Targeting Si-N Linkages. Langmuir 2013, 29, 13-28.

(11) Tian, F.; Taber, D. F.; Teplyakov, A. V. -NH- Termination of the Si(111) Surface by Wet Chemistry. J. Am. Chem. Soc. 2011, 133, 20769-20777.

(12) Tian, F.; Cui, Y.; Teplyakov, A. V. Nitroxidation of HTerminated $\operatorname{Si}(111)$ Surfaces with Nitrobenzene and Nitrosobenzene. J. Phys. Chem. C 2014, 118, 502-512.

(13) Tao, F.; Lai, Y. H.; Xu, G. Q. Si-C(N) $\sigma$ Linkages and $\mathrm{N} \rightarrow \mathrm{Si}$ Dative Bonding at Pyridine/Si(111)-7 × 7. Langmuir 2004, 20, 366368.

(14) Lee, J. Y.; Jung; Hong, S.; Kim, S. Double Dative Bond Configuration: Pyrimidine on $\mathrm{Ge}(100)$. J. Phys. Chem. B 2005, 109, 348-351.

(15) Kachian, J. S.; Squires, K. H.; Bent, S. F. Competing Geometric and Electronic Effects in Adsorption of Phenylenediamine Structural Isomers on the Ge(100)-2 $\times 1$ Surface. Surf. Sci. 2013, 615, 72-79.

(16) Gao, F.; Teplyakov, A. V. Reaction of Hydrazine with a Chlorine-Terminated Si(111) Surface. J. Phys. Chem. C 2014, 118, 27998-28006.

(17) Coustel, R.; Carniato, S.; Boureau, G. Thermodynamic Factors Limiting the Preservation of Aromaticity of Adsorbed Organic Compounds on $\mathrm{Si}(100)$ : Example of the Pyridine. J. Chem. Phys. 2011, 134, 234708.

(18) Cao, X.; Hamers, R. J. Interactions of Alkylamines with the Silicon (001) Surface. J. Vac. Sci. Technol., B: Microelectron. Process. Phenom. 2002, 20, 1614-1619.

(19) Cao, X.; Coulter, S. K.; Ellison, M. D.; Liu, H.; Liu, J.; Hamers, R. J. Bonding of Nitrogen-Containing Organic Molecules to the Silicon(001) Surface: The Role of Aromaticity. J. Phys. Chem. B 2001, 105, 3759-3768.

(20) Bocharov, S.; Teplyakov, A. V. Adsorption, Ordering, and Chemistry of Nitrobenzene on $\mathrm{Si}(100)-2 \times 1$. Surf. Sci. 2004, 573, 403-412.

(21) Bocharov, S.; Mathauser, A. T.; Teplyakov, A. V. Adsorption and Thermal Chemistry of Nitroethane on $\mathrm{Si}(100)-2 \times 1$. J. Phys. Chem. B 2003, 107, 7776-7782.

(22) Bent, S. F.; Kachian, J. S.; Rodríguez-Reyes, J. C. F.; Teplyakov, A. V. Tuning the Reactivity of Semiconductor Surfaces by 
Functionalization with Amines of Different Basicity. Proc. Natl. Acad. Sci. U. S. A. 2011, 108, 956-960.

(23) Mui, C.; Wang, G. T.; Bent, S. F.; Musgrave, C. B. Reactions of Methylamines at the $\mathrm{Si}(100)-2 \times 1$ Surface. J. Chem. Phys. 2001, 114, 10170-10180.

(24) Cho, J.-H.; Kleinman, L. Contrasting Structural and Bonding Properties of Trimethylamine and Dimethylamine Adsorbed on Si(001). Phys. Rev. B: Condens. Matter Mater. Phys. 2003, 68, 245314.

(25) Cho, J.; Choi, C. H. Thermal Decomposition Mechanisms of Methylamine, Ethylamine, and 1-Propylamine on $\mathrm{Si}(100)-2 \times 1$ Surface. J. Chem. Phys. 2011, 134, 194701.

(26) Cao, X.; Hamers, R. J. Silicon Surfaces as Electron Acceptors: Dative Bonding of Amines with $\mathrm{Si}(001)$ and $\mathrm{Si}(111)$ Surfaces. J. Am. Chem. Soc. 2001, 123, 10988-10996.

(27) Mui, C.; Han, J. H.; Wang, G. T.; Musgrave, C. B.; Bent, S. F. Proton Transfer Reactions on Semiconductor Surfaces. J. Am. Chem. Soc. 2002, 124, 4027-4038.

(28) Cao, X.; Hamers, R. J. Formation of a Surface-Mediated Donor-Acceptor Complex: Coadsorption of Trimethylamine and Boron Trifluoride on the Silicon (001) Surface. J. Phys. Chem. B 2002, $106,1840-1842$.

(29) Lozano, J.; Early, D.; Craig, J. H.; Wang, P. W.; Kimberlin, K. R. HREELS, TPD and ESD Study of Electron-Induced Decomposition of Trimethylamine on $\mathrm{Si}(100)$ at $100 \mathrm{~K}$. Surf. Interface Anal. 2005, 37, 366-373.

(30) Hossain, M. Z.; Machida, S.-I.; Nagao, M.; Yamashita, Y.; Mukai, K.; Yoshinobu, J. Highly Selective Surface Lewis Acid-Base Reaction: Trimethylamine on $\operatorname{Si}(100) c(4 \times 2)$. J. Phys. Chem. B 2004, 108, 4737-4742.

(31) Hossain, M. Z.; Machida, S.-I.; Yamashita, Y.; Mukai, K.; Yoshinobu, J. Purely Site-Specific Chemisorption and Conformation of Trimethylamine on $\operatorname{Si}(100) c(4 \times 2)$. J. Am. Chem. Soc. 2003, 125, 9252-9253.

(32) Naitabdi, A.; Bournel, F.; Gallet, J.-J.; Markovits, A.; Rochet, F.; Borensztein, Y.; Silly, M. G.; Sirotti, F. Triethylamine on Si(001)- $(2 \times$ 1) at $300 \mathrm{~K}:$ Molecular Adsorption and Site Configurations Leading to Dissociation. J. Phys. Chem. C 2012, 116, 16473-16486.

(33) Hossain, M. Z.; Mukai, K.; Yamashita, Y.; Kawai, H.; Yoshinobu, J. Real-Space Observation of Local Anisotropic Correlation between Buckled Dimers on $\mathrm{Si}(100)$ Induced by a Bidentate Adsorbed Molecule. Chem. Commun. 2011, 47, 10392-10394.

(34) Mathieu, C.; Bai, X.; Gallet, J. J.; Bournel, F.; Carniato, S.; Rochet, F.; Magnano, E.; Bondino, F.; Funke, R.; Köhler, U.; et al. Molecular Staples on Si(001)-2 $\times 1$ : Dual-Head Primary Amines. J. Phys. Chem. C 2009, 113, 11336-11345.

(35) Naderi, M.; Pickett, J. L.; Chinn, M. J.; Brown, D. R. Modified Mesoporous Silicates for the Adsorption and Decomposition of Toxic Gases. J. Mater. Chem. 2002, 12, 1086-1089.

(36) Wren, J. C.; Long, W.; Moore, C. J.; Weaver, K. R. Modeling the Removal and Retention of Radioiodine by Teda-Impregnated Charcoal under Reactor Accident Conditions. Nucl. Technol. 1999, $125,13-27$.

(37) Kim, S.; Byl, O.; Yates, J. T., Jr. The Adsorption of Triethylenediamine on $\mathrm{Al}_{2} \mathrm{O}_{3}$-I: A Vibrational Spectroscopic and Desorption Kinetic Study of Surface Bonding. J. Phys. Chem. B 2005, 109, 3499-3506.

(38) Kim, S.; Byl, O.; Yates, J. T., Jr. The Adsorption of Triethylenediamine on $\mathrm{Al}_{2} \mathrm{O}_{3}$-II: Hydrogen Bonding to $\mathrm{Al}-\mathrm{OH}$ Groups. J. Phys. Chem. B 2005, 109, 3507-3511.

(39) Kim, S.; Byl, O.; Yates, J. T., Jr. Adsorption of Triethylenediamine on $\mathrm{Al}_{2} \mathrm{O}_{3}$-III: Bonding to Lewis Acid $\mathrm{Al}^{3+}$ Sites. J. Phys. Chem. B 2005, 109, 6331-6333.

(40) Cowie, B. C. C.; Tadich, A.; Thomsen, L. The Current Performance of the Wide Range (90-2500 EV) Soft X-Ray Beamline at the Australian Synchrotron. AIP Conf. Proc. 2010, 1234, 307-310.

(41) Gomoyunova, M. V.; Pronin, I. I. Photoelectron Spectroscopy of Atomic Core Levels on the Silicon Surface: A Review. Tech. Phys. 2004, 49, 1249-1279.
(42) O’Donnell, K. M.; Warschkow, O.; Suleman, A.; Fahy, A.; Thomsen, L.; Schofield, S. R. Manipulating the Orientation of an Organic Adsorbate on Silicon: A NEXAFS Study of Acetophenone on Si (001). J. Phys.: Condens. Matter 2015, 27, 054002.

(43) Casa XPS Version 2.3.16, Casa Software Ltd.: Teignmouth, UK, 2010.

(44) Watts, B.; Thomsen, L.; Dastoor, P. C. Methods in Carbon KEdge NEXAFS: Experiment and Analysis. J. Electron Spectrosc. Relat. Phenom. 2006, 151, 105-120.

(45) Frisch, M. J.; Trucks, G. W.; Schlegel, H. B.; Scuseria, G. E.; Robb, M. A.; Cheeseman, J. R.; Scalmani, G.; Barone, V.; Mennucci, B.; Petersson, G. A. et al. Gaussian 09, Revision B.01, Gaussian, Inc.: Wallingford, CT, 2009.

(46) Becke, A. D. A New Mixing of Hartree-Fock and Local DensityFunctional Theories. J. Chem. Phys. 1993, 98, 1372-1377.

(47) Lee, C.; Yang, W.; Parr, R. G. Development of the Colle-Salvetti Correlation-Energy Formula into a Functional of the Electron Density. Phys. Rev. B: Condens. Matter Mater. Phys. 1988, 37, 785-789.

(48) Peverati, R.; Baldridge, K. K. Implementation and Performance of DFT-D with Respect to Basis Set and Functional for Study of Dispersion Interactions in Nanoscale Aromatic Hydrocarbons. J. Chem. Theory Comput. 2008, 4, 2030-2048.

(49) Beheshtian, J.; Baei, M. T.; Peyghan, A. A. Theoretical Study of CO Adsorption on the Surface of BN, AlN, BP and AlP Nanotubes. Surf. Sci. 2012, 606, 981-985.

(50) Okamoto, Y. Initial Stage of the Catalyzed Growth of $\mathrm{SiO}_{2}$ Films on Si(001): An Ab Initio Study. J. Phys. Chem. B 1999, 103, 11074-11077.

(51) Leftwich, T. R.; Teplyakov, A. V. Calibration of Computationally Predicted N 1s Binding Energies by Comparison with X-Ray Photoelectron Spectroscopy Measurements. J. Electron Spectrosc. Relat. Phenom. 2009, 175, 31-40.

(52) Wada, T.; Kishida, E.; Tomiie, Y.; Suga, H.; Seki, S.; Nitta, I. Crystal Structure and Thermodynamical Investigations of Triethylenediamine. Bull. Chem. Soc. Jpn. 1960, 33, 1317-1318.

(53) Redhead, P. A. Thermal Desorption of Gases. Vacuum 1962, 12, 203-211.

(54) Clemen, L.; Wallace, R. M.; Taylor, P. A.; Dresser, M. J.; Choyke, W. J.; Weinberg, W. H.; Yates, J. T., Jr. Adsorption and Thermal Behavior of Ethylene on $\mathrm{Si}(100)-(2 \times 1)$. Surf. Sci. 1992, 268, 205-216.

(55) Bulanin, K. M.; Shah, A. G.; Teplyakov, A. V. Infrared Spectroscopy Studies of Iodoethane on $\mathrm{Si}(100)-2 \times 1$ : Adsorption and Thermal Decomposition Leading to Adsorbate Ordering. J. Chem. Phys. 2001, 115, 7187-7195.

(56) Widdra, W.; Huang, C.; Briggs, G. A. D.; Weinberg, W. H. Ethylene and Coadsorbed Hydrogen on $\operatorname{Si}(100)-(2 \times 1)$ : Structure, Bonding, and Decomposition. J. Electron Spectrosc. Relat. Phenom. 1993, 64-65, 129-136.

(57) Fauquet, C.; Dannetun, P.; Fredriksson, C.; Stafström, S.; Bourée, J. E.; Brillaud, P.; Bouanah, N.; Salaneck, W. R. Electronic Structure of Trimethylamine Alane in the Solid State. Chem. Phys. Lett. $1995,235,528-534$

(58) Kang, D.-H.; Chatterjee, B.; Herceg, E.; Trenary, M. Adsorption and Decomposition of Trimethylamine on $\mathrm{Pt}(111)$ : Formation of Dimethylaminocarbyne $\left(\mathrm{CN}\left(\mathrm{CH}_{3}\right)_{2}\right)$. Surf. Sci. 2003, 540, 23-38.

(59) Jack, J. J.; Hercules, D. M. Electron Spectroscopy of Quaternary Nitrogen Compounds. Anal. Chem. 1971, 43, 729-736.

(60) Deng, Z. W.; Souda, R. XPS Studies on Silicon Carbonitride Films Prepared by Sequential Implantation of Nitrogen and Carbon into Silicon. Diamond Relat. Mater. 2002, 11, 1676-1682.

(61) Miyoshi, K.; Buckley, D. H. XPS, AES and Friction Studies of Single-Crystal Silicon Carbide. Appl. Surf. Sci. 1982, 10, 357-376.

(62) Khaliq, A.; Pierucci, D.; Tissot, H.; Gallet, J.-J.; Bournel, F.; Rochet, F.; Silly, M.; Sirotti, F. Ene-Like Reaction of Cyclopentene on Si(001)-2 × 1: An XPS and NEXAFS Study. J. Phys. Chem. C 2012, $116,12680-12686$.

(63) Stöhr, J. NEXAFS Spectroscopy. Springer-Verlag, Berlin, Heidelberg, 1992. 
(64) Turci, C. C.; Urquhart, S. G.; Hitchcock, A. P. Inner-Shell Excitation Spectroscopy of Aniline, Nitrobenzene, and Nitroanilines. Can. J. Chem. 1996, 74, 851-869.

(65) Huang, S. X.; Fischer, D. A.; Gland, J. L. Correlation between the Surface Configurations and Hydrogenolysis: Aniline on the Pt(111) Surface. J. Vac. Sci. Technol., A 1994, 12, 2164-2169. 